\title{
Albert Vigoleis Thelen: ecos literários de um exílio em Portugal ${ }^{1}$
}

\section{Maria Antónia Gaspar Teixeira}

Universidade do Porto - ILC

\begin{abstract}
Resumo: Com uma obra que se relaciona intimamente com a sua biografia, Albert Vigoleis Thelen foi um autor em contracorrente. Após alguns apontamentos sobre a sua vida de errância e as particularidades narrativas que mais o distinguiram, centrar-me-ei no eco literário do seu exílio em Portugal.
\end{abstract}

Palavras-chave: Thelen, exílio, Portugal, Teixeira de Pascoaes

\begin{abstract}
With a work closely related to his biography, Albert Vigoleis Thelen was an author in countercurrent. After a few notes on his life of wandering and the narrative characteristics that most distinguished him, the A. will focus on literary echoes of his exile in Portugal.
\end{abstract}

Keywords: Thelen, exile, Portugal, Teixeira de Pascoaes 
Consensualmente reconhecido como um dos raros escritores cuja obra literária se relaciona íntima e produtivamente com o seu percurso biográfico, o poliglota Albert Thelen, que adotou o nome de Vigoleis - alcunha trocista que lhe puseram devido ao seu interesse pelo romance cortês Wigalois, e que Thelen também irá atribuir, como se verá, ao herói de vários dos seus textos -, cedo abandonou o seu país numa longa vida de errância que duraria cerca de 55 anos. Sem terminar o liceu, e depois de diversas formações e profissões técnicas (e.g. serralharia, tecelagem), às quais se seguiu uma breve passagem pelas universidades de Colónia e de Münster, também interrompida, onde frequentou seminários de germanística, filosofia, filologia neerlandesa, etc. (Pütz 1990: 22-24), Thelen decidiu virar costas ao seu país, em 1931. Não por questões de ligação ao judaísmo, porque nasceu numa família muito católica, mas por dificuldades económicas e também devido ao desconforto que sentia pelo que politicamente se anunciava na Alemanha, rumou a Amsterdão na companhia da futura mulher, a suíça Beatrice Bruckner. Ainda no mesmo ano, segue-se Maiorca onde, sempre à beira da miséria, se dedica a diversos trabalhos de ocasião (e.g. recensor de literatura alemã do exílio para um jornal holandês, secretário particular, guia turístico). Todavia, o que teve início voluntariamente - socorrer um irmão de Beatrice que se dizia às portas da morte -, acabou por se transformar num exílio político forçado e numa fuga pela vida através de meia Europa. De facto, com o deflagrar da guerra civil espanhola e a chegada dos falangistas às Canárias, em 1936, o casal vê-se obrigado a fugir. É que as posições oficiais entretanto assumidas por Thelen em relação ao nacionalsocialismo (recusa, p. ex., prestar o juramento de fidelidade ao Führer) haviam-no tornado, tanto para o consulado alemão da ilha como para os falangistas espanhóis, uma figura suspeita, e por muito pouco escapou a uma ordem de fuzilamento (Pütz 1990: 26). 0 casal Thelen evade-se para a Suíça, onde residirá entre 1937-39. Porém, devido à crescente insegurança que aí sentiam resultante da vigilância persecutória da Gestapo, e em íntima articulação com uma muito oportuna troca de correspondência entre Thelen e Teixeira de Pascoaes que se iniciara em junho de 1935 e se prolongará até à morte do autor português, realizam finalmente o projeto anunciado desde 1937 de se refugiarem em Portugal (Thelen 1997: 63). É que, logo em outubro de 1936, Pascoaes havia convidado o confrade alemão 
para o seu solar em São João de Gatão, perto de Amarante (Caeiro 1990: 40). Depois de diversos protelamentos, em grande medida por questões burocráticas, ${ }^{2}$ o casal segue mesmo nas vésperas do deflagrar da Segunda Guerra Mundial, já não o trajeto inicialmente previsto, via Rotterdam e de barco de carga até ao Porto (Thelen 1997: 88), mas a rota mais direta, por Bordéus. Conseguidos os vistos para Portugal, com assinatura de Aristides de Sousa Mendes (Pimentel 2008: 100), e depois de uma tormentosa fuga através da Espanha franquista, passam a fronteira de Vilar Formoso a 31 de agosto de 1939. Chegam ao solar da Pascoaes no dia seguinte, o fatídico dia da invasão da Polónia, dando início a um exílio de quase oito anos que anteriormente haviam projetado como uma curta estadia de cerca de seis meses (Thelen 1997: 78). Vivem então uma fase relativamente calma, num isolamento que muito se acentua quando, a partir do verão de 1942, habitam numa outra casa de Pascoaes, em Travanca do Monte, devido a uma tuberculose de Thelen - doença essa que, debelada, terá servido de pretexto para evitar a mobilização que os nacional-socialistas então faziam dos alemães residentes no estrangeiro. De facto, em carta de julho de 1944, Pascoaes recebe o seguinte comentário no colorido português do seu protegido: “Oxalá que o curso da guerra vá de maneira a não me forçar mais de tomar a atitude de tuberculoso perigoso perante o consulado alemão" [sic] (Thelen 1997: 117). Todavia, em 1947, a Polícia de Vigilância e Defesa do Estado (PVDE) não renova a necessária autorização de permanência no país (Franco 2014: 207). ${ }^{3}$ Apesar de, tal como os outros refugiados, já poder nessa data regressar à Alemanha, opta por uma continuação do exílio, dado repudiar a permanência de responsáveis nazis em posições de chefia no após-guerra (Pütz 1990: 25). Com visitas regulares a Portugal - a última em 1976 - para rever Pascoaes e família (Caeiro 1990: 48) e outras, raras, à Alemanha (Thelen 1997: 145,170), residirá primeiro sete anos em Amsterdão (1947-54), depois mais de 30 na Suíça (1954-86) e, embora entretanto oficialmente reconhecido como perseguido pelo regime nacional-socialista (1962), apenas em 1986 regressará à sua região natal, na Renânia do Norte-Vestfália, vindo aí a falecer três anos depois.

A esta biografia pouco habitual corresponde um percurso literário, também ele em contracorrente, o que levará Pütz a considerar Thelen um outsider, um autor fora do seu 
tempo (Pütz 1990: 14-15).

Assim, e apesar da sua importância, quer no âmbito da literatura alemã, quer no da divulgação internacional da literatura portuguesa, apenas nas últimas décadas tem vindo a ser (re)descoberto (Schäfer 1990: 175). De facto, as suas escassas e tardias publicações, ao que se aliava uma escrita nos antípodas da orientação literária do mais influente agrupamento de escritores de língua alemã do após-guerra que era o “Grupo 47", e talvez ainda a insistência no exílio voluntário depois do final da guerra, não terão propiciado a popularidade de Thelen na Alemanha.

Na sua vasta obra - muita não editada (Pütz 1990: 57) -, destaca-se o primeiro romance que publicou, quando já contava 50 anos: Die Insel des zweiten Gesichts. Aus den angewandten Erinnerungen des Vigoleis (1953) [“A ilha do segundo rosto. Das memórias aplicadas de Vigoleis"]. Espelho das peripécias vividas por Thelen em Maiorca nos anos 30 entrelaçadas com o tratamento humorístico-satírico, frequentemente de cariz antifascista, ${ }^{4}$ dos acontecimentos da época, na qual se move um leque muito diversificado de figuras, Die Insel é uma obra entre autobiografia e romance, mais propriamente de "memórias aplicadas", como se lê em subtítulo. E "memórias aplicadas" porque uma das marcas estruturais da escrita de Thelen - para além de um discurso muito próprio e das longas reflexões, associações e digressões constantes, por vezes mais importantes do que a própria narrativa -, é uma relação de tensão entre elementos autobiográficos e fictícios, ao que se alia uma duplicação do narrador. Mais concretamente: as memórias são narradas por um eu omnisciente que, nos anos 50, revê as aventuras passadas em Maiorca, na década de 30, e em cujo discurso se entretece o de um segundo narrador que é Vigoleis, o herói do romance, espécie de alter-ego de Thelen que vive essas aventuras, mas dotado de menos-saber e frequentemente referido na terceira pessoa (Schäfer 1990: 176-177; Pütz 1990: 151-153, passim). Embora tenha constituído um êxito de mercado e tenha valido ao autor o Prémio Fontane (1954), a receção de Die Insel não foi consensual entre a crítica literária. Aplaudido encomiasticamente por uns (p. ex., Siegfried Lenz, Paul Celan) como uma das grandes obras do século XX, o romance foi duramente repudiado, como seria de esperar, pelo spiritus rector do "Grupo 47" quando, em 1953, Thelen fez uma leitura perante o grupo. 
"Emigrantendeutsch" [Alemão de emigrante], foi a sentença de Hans Werner Richter (Jung 2005: 22), confrontado com as particularidades do discurso do autor, transbordante, meândrico, recheado de neologismos, arcaísmos, regionalismos e coloquialismos.

Thelen não voltou a escrever um único livro que a crítica literária recebesse favoravelmente, e depressa caiu no esquecimento de décadas. Bastará lembrar, p. ex., o acolhimento mais do que reservado ao seu segundo grande romance em torno da fase na Holanda, nos anos 40-50, que são as "memórias aplicadas" Der schwarze Herr Bahßetup. Ein Spiegel (1956) [“O escuro senhor Bahßetup. Um espelho”].

Decerto mais interessante para nós é que, quase 20 anos antes de qualquer publicação própria, já Thelen se entregava à tradução de um autor português, o que foi determinante para a sua longa estadia no nosso país. ${ }^{5}$ De facto, a história prévia da vinda do autor alemão para Amarante foi um verdadeiro fascínio pela obra de Teixeira de Pascoaes. ${ }^{6}$ Talvez de início por cortesia para com o seu anfitrião in spe, a verdade é que, já em carta de novembro de 1937, Thelen considera que chegará o dia em que terão de conceder o Prémio Nobel ao poeta do Marão (Thelen 1997: 69), e, em 1941, contacta inclusivamente Thomas Mann para que este, enquanto antigo laureado, proponha a atribuição do Prémio Nobel de Literatura ao escritor e místico português (Pütz, 1990: 28). Ou lembre-se ainda a fundação da "Sociedade Internacional Pascoaense S. A. Auressio", na Suíça, de que dá notícia a Pascoaes em carta de fevereiro de 1939 (Thelen 1997: 86).

Como é narrado em Die Insel e relatado por Caeiro (1990: 28ss.), em 1935, quando ainda se encontrava em Maiorca, Thelen descobriu de modo burlesco a versão castelhana da biografia romanceada São Paulo (1934), de Teixeira de Pascoaes. Deslumbrado, sobretudo com a nova interpretação do Cristianismo que lhe era dado ler, logo iniciou a referida troca de correspondência com o poeta. Começando sem demora a aprender português - que viria a tornar-se a língua utilizada quotidianamente por Thelen e Beatrice (Thelen 1997: 169) -, propõe encarregar-se da tradução de São Paulo para alemão e, de parceria com o escritor modernista e amigo Hendrik Marsman, para holandês (Thelen 1997: 53-54). Tomaria ainda em mãos as diligências necessárias para a divulgação internacional dessa obra que se tornou, nas suas palavras, "das große Abenteuer meines 
Lebens" (Thelen 1983: 672) [a grande aventura da minha vida]. Dos progressos e problemas da tradução que ia fazendo e, sobretudo, dos desesperantes contactos com as mais diversas casas editoras europeias, vai Thelen dando regularmente conta nas cartas que envia a Pascoaes. Terminada ainda em 1935 e depois de recusada por 37 editoras, a tradução de São Paulo será enfim publicada, em 1937, em versão holandesa, ao que se seguirá, em 1938, a edição da versão alemã. 0 êxito, principalmente da versão holandesa, foi grande, tanto junto da crítica como do mercado literário. Pascoaes dirá que em dois dias se venderam 1500 exemplares (Franco 2014: 107). Os contratempos entretanto sofridos com o retardamento da publicação de São Paulo não esmoreceram o entusiasmo de Thelen e de Marsman pelo autor português. Em 1936-37, ambos passam à tradução de São Jerónimo e a trovoada (1936), 7 pouco depois à de Verbo escuro (1914). Thelen traduzirá ainda Napoleão (1940), cuja versão holandesa terá a colaboração de Gerard Diels devido ao falecimento de Marsman, bem como Duplo passeio (1942), apenas para alemão. ${ }^{8}$

Da vinda para Portugal e da estadia de quase oito anos no país como convidado de Pascoaes esperar-se-ia uma continuação de Die Insel. Seria um terceiro volume de grande fôlego de "memórias aplicadas", agora sobre as peripécias vividas entre nós entretecidas com as esperadas reflexões, digressões e arabescos, frequentemente de clave humorística e/ou satírica, de modo a preencher o hiato entre o tempo narrado no romance maiorquino e em "O escuro senhor Bahßetup". Sabe-se que, ainda em Portugal, Thelen aquiesceu ao pedido de um editor holandês nesse sentido (Thelen 1997: 123). Sabe-se ainda que, mais tarde, chegou a fazer uma leitura pública de um dos fragmentos que integraria a referida obra. De facto, no início de um áudio-livro gravado em 1966, que constitui uma rara mistura entre literatura oral e escrita, e antecedendo uma crítica demolidora, por vezes em tom apocalíptico, ao nacional-socialismo e à grande base social que o suportava, ${ }^{9}$ o brilhante narrador oral que era Thelen introduz a leitura que se seguirá nos seguintes termos:

"Ich lese Ihnen heute Abend (...) einen Kapitel aus einem unveröffentlichten Buch, an dem ich lange gearbeitet habe. Ich habe wegen eines Augenleidens sieben Jahre nicht lesen und schreiben können und dann zieht sich das alles so in die Länge und im Buch selber zieht sich alles auch wieder in die Länge; also, es wird ein unendlich großes Buch werden. Was ich lese ist also aus einem Manuskript 
von etwa neunhundert Seiten, das Ganze geht in die Tausende von Seiten und es heißt ja auch immer, dass ich aus dem Hundertsten ins Tausendste komme und manchmal sogar in die Million. Das Buch trägt den alles überwölbenden Titel 'Die Gottlosigkeit Gottes oder Das Gesicht der zweiten Insel'. Gottlosigkeit Gottes darum, weil im Mittelpunkt des Buches die Gestalt meines mystischen Freundes, Teixeira de Pascoaes, steht, des portugiesischen Dichters, dessen Werke / Bücher ich ins Holländische und ins Deutsche übersetzt habe und im Mittelpunkt der Bemühung von Pascoaes steht der Gedanke des religiösen Atheismus." (Thelen 1966: CD 1)

[Hoje à noite vou-vos ler (...) um capítulo de um livro não publicado, no qual trabalhei muito tempo. Devido a uma doença nos olhos não pude ler e escrever durante sete anos, e então tudo se prolonga e também no próprio livro tudo se prolonga; vai ser um livro infinitamente longo. 0 que vou ler, é de um manuscrito de cerca de novecentas páginas, vai até ao milhar de página s e também se diz sempre que de cem faço mil e às vezes até um milhão. 0 livro tem o título englobante de "O ateísmo de Deus ou 0 rosto da segunda ilha". Ateísmo de Deus, porque no centro do livro está a figura do meu amigo místico, Teixeira de Pascoaes, do poeta português, cujas obras e livros traduzi para holandês e alemão, e no centro das considerações de Pascoaes está a ideia do ateísmo religioso.] (Thelen 1966: CD 1) (trad. minha)

Todavia, nada na leitura suporta as expectativas criadas quanto às "memórias aplicadas" referentes a Portugal, dado que, lamentavelmente, o texto se debruça apenas sobre o tempo que antecede a entrada no nosso país. Por outro lado, ao sublinhar a sua situação mais do que privilegiada em comparação com a de muitos outros contemporâneos, em exílios terríveis ou mesmo mortos, afirma numa entrevista de 1987 não poder expor publicamente o que viu de grotesco durante a sua estadia entre nós devido a um sentimento de gratidão para com Teixeira de Pascoaes (Schäfer 1990: 180).

Terá, de facto, existido o manuscrito integral que, nesse caso, foi destruído por Beatrice para cumprir a última vontade do marido, ou fará ele parte da autoestilização do autor? Certo é que, a ter existido, o referido manuscrito nunca chegou a público. Apenas sobreviveram três fragmentos, publicados em periódicos nos anos 70 e postumamente coligidos em Poetische Märzkälbereien [Tolices poéticas em março] (Thelen 1990: 12-73, 74-107, 108-120). São eles: “Der Hirtenbrief” (1979) [“A carta pastoral”], “Grenzstein der Freiheit" (1975) ["Marco da liberdade"] - que integra a referida gravação - e "Die Gottlosigkeit Gottes oder das Gesicht der zweiten Insel" (1974) [0 ateísmo de Deus ou 0 
rosto da segunda ilha] - textos já traduzidos e comentados por Caeiro (1990: 41ss.). Porém, os dois primeiros textos que referi incidem sobre a travessia da Espanha, terminando o segundo precisamente com a chegada a Vilar Formoso que, nas palavras do revisor do "Lusitânia-Expresso", marca a fronteira da liberdade (Thelen 1990: 107). Assim sendo, e no que toca aos ecos literários da fase portuguesa de Thelen, os leitores de pouco mais dispõem do que da terceira narrativa referida - também conhecida sob o título de "Die geweiste Flucht" ["A fuga indigitada”] (Caeiro 1990: 42, 100) -, bem como de "Tabakpanik" (1955) ["Pânico tabágico"]. De facto, se se atender ainda a algumas digressões nos dois grandes romances e à estreia literária de Thelen que foi a publicação da coletânea lírica Schloss Pascoaes (1942) ["Solar de Pascoaes"], dedicada ao anfitrião e na qual se tematiza a chegada ao solar, o interior da casa e a respetiva moldura exterior (Caeiro 1990: 110-187), encontra-se reunido o escasso registo literário da estadia de Thelen em solo português.

"O ateísmo de Deus" - que retrata a vertiginosa viagem de carro do Porto até ao solar de Amarante e é construído com vista ao clímax constituído pela chegada ao momento e espaço da salvação que é a entrada no solar e o primeiro encontro físico com Pascoaes oferece uma imagem dupla, simultaneamente eufórica e disfórica do país. Por um lado, Portugal é de uma surpreendente hospitalidade, o refúgio da guerra devido à generosidade do anfitrião. Por outro lado, ao longo de todo o texto ressalta uma atitude crítica em relação à grande clivagem social e económica existente no norte rural do país. Embora com pinceladas de humor, é retratada a vida arcaica dos camponeses, marcada por uma extrema pobreza aliada a uma notória humildade. 10 Em flagrante contraste, os "muitos criados" (Caeiro 1990: 107) de Pascoaes, ou os "carros de luxo tipo Rolls-Royce, pertença dos grandes senhores, com elegantes chauffeurs de bata branca" (Caeiro 1990: 102), a cuja passagem os camponeses se descobrem com respeito.

Surpreendente se me afigura que desta visão crítica quanto à miséria e ao atraso que tanto parece incomodar Thelen não resulte qualquer ilação sobre a situação sociopolítica do nosso país. Nem numa longa interpelação à figura de Vigoleis, de quem o narrador se distancia, se vai além das difíceis, porque muito diferenciadas formas de tratamento em português. ${ }^{11}$ De resto, também nas cartas a Pascoaes, elaboradas para se manterem no 
estrito espaço privado, o autor não se alarga em qualquer comentário de caráter político sobre Portugal.12 As críticas, mais do que contidas, em pouco ultrapassam o mau funcionamento do correio português (Thelen, 1997: 105), ou ainda, demarcando-se do Outro, o "sofrimento" que lhe causa o atraso e a pobreza extremas na "Travanca medieval em pleno século vinte", de que resultará "um capítulo muito triste nas minhas futuras memórias de viagens através da Europa" (Thelen 1997: 98, 99). Todavia, será curioso notar, num parêntesis, que Thelen esquece com ligeireza a referida reserva quando se trata da germanística portuguesa na pessoa de Paulo Quintela. Leia-se na carta de 17 de julho de 1944:

“O tradutor português de Hölderlin é o professor Paulo Quintela de Coimbra, antigo leitor de português na universidade de Berlim. Traduziu também muitas coisas de Rilke. Junto com o Eduardo e o Ernesto comparámos as traduções cuidadosamente com o original. Tanto filologicamente como poeticamente afigura-se-me um fracasso". (Thelen 1997: 117)

Já "Pânico tabágico" gira em torno de um fait divers de cariz anedótico da vida do grande fumador que era Pascoaes, cujo comportamento numa loja de tabaco portuense é considerado muito suspeito pelo comerciante. De permeio, e ombreando com as habituais digressões - p. ex., sobre os contratos entre autores e editores, nada lucrativos para os primeiros -, são-nos dados breves apontamentos sobre alguns, poucos, aspetos do panorama social do Porto. Como é frequente em textos de exilados no nosso país, evocamse os cafés enquanto espaços sociais e culturais masculinos (onde homens de negócios se cruzam com poetas nada produtivos e ociosos conversadores). Por seu turno, adotando a perspetiva crítica do incomodado comerciante mas dela se distanciando simultaneamente, o narrador não idealiza os refugiados e aponta, com algum humor, certos estratagemas, alguns mesmo condenáveis, a que aqueles recorrem para sobreviver na situação extrema em que se encontram. Recorde-se o início do longo comentário do narrador:

\footnotetext{
“In jenen Tagen streunten hungrige Flüchtlinge aller Zungen durchs Land; man hatte schon Läden geplündert; manch einer war mit der Zeche durchgebrannt, der zuhause nicht einmal die Kirchensteuer zu hinterziehen gewagt hätte. Der Mitmensch des auf den ersten Blick so reichen und
} 
über die Maßen gastfreundlichen Landes wurde geprellt, wo immer es anging. Man war auf der Hut". (Thelen 1990: 129)

[Naquele tempo vagueavam pelo país refugiados famintos, de todos os idiomas; já algumas lojas tinham sido pilhadas; muitos deles, que na sua terra não ousariam sequer deixar em dívida o imposto para a Igreja, tinham fugido sem pagar a conta duma bebida. 0 cidadão daquele país à primeira vista tão rico, e sobretudo tão hospitaleiro, era intrujado onde calhava. Vivia-se em estado de alerta]. (Caeiro 1990: 194)

Enquanto mediador intercultural, Thelen tem o mérito indiscutível, não apenas de se ter antecipado a qualquer outro comentador, mesmo português, quanto ao estudo aprofundado e ao reconhecimento da importância da obra e do pensamento de Teixeira de Pascoaes (Franco 2014: 17), mas também de se ter dedicado infatigavelmente à sua divulgação entre editores e escritores da Europa de além-Pirenéus. Por outro lado, e longe do que seria de esperar, não se pode negar uma certa desilusão que as cartas a Pascoaes também não compensam quanto à escassez e à superficialidade dos ecos literários do seu exílio em Portugal, tanto mais que, no seu dizer, foi "o primeiro e único país, que me deixou saudades" (Thelen 1997: 133). 


\section{Bibliografia}

Caeiro, Olívio (1987), “Duas imagens de Portugal na literatura alemã do séc. XX: Albert Vigoleis Thelen e Johannes Schenk", Runa, revista portuguesa de estudos germanísticos, n.․ 7-8, 173-201.

-- (1990), Albert Vigoleis Thelen no solar de Pascoaes, Porto, Brasília.

Franco, António C. (2014), Trinta anos de dispersos sobre Teixeira de Pascoaes, http://dspace.uevora.pt

Hanssen, Léon (2005), "Einem größeren Antipoden bin ich in der Literatur selten begegnet", Ter Braak - Thelen - Pascoaes", in Heinz Eickmans / Lut Missine (eds.), Albert Vigoleis Thelen. Mittler zwischen Sprachen und Kulturen, Münster/New York/München/Berlin, Waxsmann, 137-145.

Jung, Werner (2005), "Faschismuskritik und Deutschlandbild in Die Insel des zweiten Gesichts. Zur Dimension von Albert Vigoleis Thelens Zeitkritik", in Heinz Eickmans / Lut Missine (eds.), Albert Vigoleis Thelen. Mittler zwischen Sprachen und Kulturen, Münster/New York/München/Berlin, Waxsmann, 21-29.

Pascoaes, Teixeira de (1938), Paulus. Der Dichter Gottes [São Paulo, 1934], trad. de Albert Vigoleis Thelen, Zürich, Rascher Verlag.

-- (1941), Hieronymus. Der Dichter der Freundschaft. Aus dem Portugiesischen übertragen von Albert Vigoleis Thelen [São Jerónimo e a trovoada,1936] Amsterdam; Leipzig, Tiefland.

-- (1949), Das dunkle Wort. Aus dem Portugiesischen übertragen von Albert Vigoleis Thelen, [Verbo escuro, 1914], Zürich, Rascher-Verlag.

-- (1997), Napoleon. Spiegel des Antichrist. Aus dem Portugiesischen übersetzt und mit einem Text über Pascoaes von Albert Vigoleis Thelen [Napoleão, 1940], Bonn, Weidle Verlag.

Pimentel, Irene Flunser (2008), Judeus em Portugal durante a II Guerra Mundial. Em fuga de 
Hitler e do Holocausto, Lisboa, Esfera dos Livros.

Pütz, Jürgen (1990), Doppelgänger seiner selbst: der Erzähler Albert Vigoleis Thelen, Wiesbaden, Westdeutscher Verlag.

Schäfer, Ansgar (1990), "Albert Vigoleis Thelen e Teixeira de Pascoaes", Colóquio/Letras, n.. $113 / 114,175-181$.

Thelen, Albert Vigoleis (1942), Schloß Pascoaes, Zürich, Rhein-Verlag.

-- (1983), Die Insel des zweiten Gesichts. Aus den angewandten Erinnerungen des Vigoleis. Roman. Ungekürzte Ausgabe, Frankfurt/Main, Berlin, Ullstein. [11953]

-- (1990), Poetische Märzkälbereien. Gesammelte Prosa, hrsg. von Werner Jung, Mönchengladbach, Juni.

-- (1997), Cartas a Teixeira de Pascoaes [1935-1952], org., introd. e tábua biobibliográfica de A. V. T. de A. C. Franco, Lisboa, Assírio e Alvim.

-- (2001), Die Gottlosigkeit Gottes oder Das Gesicht der zweiten Insel. Gelesen und frei vorgetragen von Albert Vigoleis Thelen, 2 CDs, Edition Die Horen, Bremerhaven. [gravação de 1966] 
Maria Antónia Gaspar Teixeira licenciou-se em Filologia Germânica pela Faculdade de Letras da Universidade de Coimbra, em 1974, onde obteve também o grau de Mestre em Literatura Alemã e Comparada, em 1992, com um estudo sobre a receção portuguesa do drama Mutter Courage und ihre Kinder. Doutorou-se na Universidade do Porto, em 2007, com um estudo sobre a receção portuguesa do romance Die Leiden des jungen Werthers. Desde 1974 exerce funções docentes na Faculdade de Letras da Universidade do Porto, onde ocupa atualmente o lugar de Professora Auxiliar. Membro do Centro Interuniversitário de Estudos Germanísticos desde a sua fundação, passou a integrar, em 2007, o Instituto de Literatura Comparada Margarida Losa. Para além de diversos artigos em publicações da especialidade, maioritariamente na área da receção e da crítica da tradução literárias (e.g. Apontamentos sobre a versão portuguesa da peça Biedermann und die Brandstifter, 2012; Zur Münchhausen-Rezeption in Portugal: eine Fallstudie, 2013), é coautora da obra Do Pobre B. B. em Portugal (Minerva/Centro Interuniversitário de Estudos Germanísticos, 1998) e autora de A Recepção Portuguesa de Die Leiden des jungen Werthers (desde 1784 até Finais do Primeiro Romantismo) (MinervaCoimbra/Centro de Investigação em Estudos Germanísticos, 2009). As suas principais áreas de investigação são as relações culturais e literárias luso-alemãs, a receção portuguesa de autores de língua alemã e a crítica da tradução literária. 


\section{NOTAS}

${ }^{1}$ Este artigo foi desenvolvido no âmbito do Programa Estratégico integrado UID/ELT/00500/2013 | POCI-010145-FEDER-007339

2 P. ex., em 24 de julho de 1939, Thelen escreve que possui finalmente os passaportes, faltando-lhe porém os diversos vistos necessários para abandonar a Suíça (Thelen 1997: 92-93).

${ }^{3}$ Segundo informação solicitada à Torre do Tombo e recebida por correio eletrónico em 8 de setembro de 2015, não existem nos arquivos da PIDE/DGS quaisquer registos relativos à presença do casal Thelen em Portugal.

${ }^{4}$ Quanto à dimensão antifascista dos escritos ficcionais de Thelen, cf. Jung 2005.

${ }^{5}$ Sobre essa estadia que, insisto, se prolongará desde o verão de 1939 até inícios de 1947, bem como quanto aos respetivos ecos literários, são incontornáveis os estudos de Olívio Caeiro $(1987 ; 1990)$ e, embora de diferente dimensão e/ou enfoque, os de Ansgar Schäfer (1990: 175-180) e de António Cândido Franco (2014), dos quais aqui se retiram diversas informações.

${ }^{6}$ Problematizando esse fascínio, nada crítico em sua opinião, Hanssen considera que apenas motivos de carreira o poderão explicar (Hanssen 2005: 144-145). Quanto às relações de Pascoaes com Albert Thelen será talvez oportuno lembrar o seu tratamento ficcionalizado no romance $O$ susto (1958), de Agustina Bessa Luís (Franco 2014: 108).

7 Segundo uma carta de Thelen a Pascoaes, datada de outubro de 1942, a versão alemã de São Jerónimo constituiu "um êxito redondo e completo" (Thelen 1997: 100), encontrando-se esgotadas as duas primeiras edições, respetivamente de 1600 e de 2000 exemplares.

8 Refletindo um problema do exílio, a edição das versões holandesas antecede sempre a das alemãs. A tradução holandesa de São Jerónimo e a trovoada foi publicada em 1939, a alemã em 1941; Verbo escuro foi publicado em holandês em 1946, em alemão em 1949; Napoleão será dado à estampa na Holanda em 1950, na Alemanha em 1997. Já Duplo passeio conta apenas com a versão alemã, publicada em 1951 numa revista de Berlim Oriental (Franco 2014: 204ss.).

9 Uma referência a Hitler bastará como exemplo: "ein dem Wahnsinn verfallener Aufrührer [richtete] Menschen zu Tieren [ab]" [um revolucionário caído na loucura transformou pessoas em animais] (CD 1).

${ }^{10}$ Leia-se, p. ex., "Dieses gemächlichere Tempo ermöglichte es uns, kleine nackte Kinder zu sehen, die sich im Mulme spielend wälzten, von kleinen Ferkeln, die mit derselben Schutzfarbe angetan waren, dennoch zu unterscheiden." (Thelen 1990: 111) [Este ritmo mais calmo [da viagem para Pascoaes] permitiu-nos ver criancinhas nuas que se rebolavam brincando na terra, distinguindo-se contudo dos leitões, que se vestiam 
com a mesma camuflagem] (Caeiro 1990: 103). Ou ainda: “(...) ich sah wieder winzige Häuser, eigentlich nur Steinblöcke mit einem Eingangsloch, strohgedeckt. (...) einige Männer zogen ihre Strohhüte und hielten sie ehrerbietig vor der Brust, auch Frauen nahmen ihre Hüte ab und ließen uns wortlos vorüberrollen;" (Thelen 1990: 114] [(...) tornei a ver casas minúsculas, propriamente simples blocos de pedra com um buraco de entrada, cobertos de palha. (...) alguns homens puxavam dos chapéus de palha, que seguravam respeitosamente junto ao peito, também mulheres tiravam o chapéu e deixavam-nos passar sem dizer palavra] (Caeiro 1990: 105).

${ }^{11}$ No entanto, é através do recurso à figura de Vigoleis que, neste texto, o narrador critica duramente o Führer e a perigosa agressividade do povo alemão (Thelen 1990: 112).

12 Mais surpreendente será, a meu ver, a quase ausência de comentários nas cartas quanto aos acontecimentos na Alemanha e à guerra que devastava a Europa por parte de um autor que rejeitava o nacional-socialismo. 